\title{
Characterization of porous silicon nitride/silicon oxynitride composite ceramics produced by sol infiltration
}

\author{
Dechang Jia ${ }^{\mathrm{a}, *}$, Yingfeng Shao ${ }^{\mathrm{b}}$, Boyang Liu ${ }^{\mathrm{c}}$, Yu Zhou $^{\mathrm{a}}$ \\ a Institute for Advanced Ceramics, Harbin Institute of Technology, Harbin 150001, China \\ b State Key Laboratory of Nonlinear Mechanics (LNM), Institute of Mechanics, Chinese Academy of Sciences, Beijing 100190, China \\ ' Institute of Marine Materials Science and Engineering, Shanghai Maritime University, Shanghai 201306, China
}

\section{A R T I C L E I N F O}

\section{Article history:}

Received 24 November 2009

Received in revised form 25 April 2010

Accepted 28 May 2010

\section{Keywords:}

Ceramics

Sintering

Dielectric properties

Mechanical properties

\begin{abstract}
A B S T R A C T
Porous silicon nitride/silicon oxynitride composite ceramics were fabricated by silica sol infiltration of aqueous gelcasting prefabricated $\mathrm{Si}_{3} \mathrm{~N}_{4}$ green compact. Silica was introduced by infiltration to increase the green density of specimens, so suitable properties with low shrinkage of ceramics were achieved during sintering at low temperature. $\mathrm{Si}_{2} \mathrm{~N}_{2} \mathrm{O}$ was formed through reaction between $\mathrm{Si}_{3} \mathrm{~N}_{4}$ and silica sol at a temperature above $1550{ }^{\circ} \mathrm{C}$. $\mathrm{Si}_{3} \mathrm{~N}_{4} / \mathrm{Si}_{2} \mathrm{~N}_{2} \mathrm{O}$ composite ceramics with a low linear shrinkage of $1.3-5.7 \%$, a superior strength of 95-180 MPa and a moderate dielectric constant of 4.0-5.0 (at 21-39 GHz) were obtained by varying infiltration cycle and sintering temperature.
\end{abstract}

(C) 2010 Published by Elsevier B.V.

\section{Introduction}

For the high temperature applications, silicon nitride ceramic has received much attractions due to its outstanding properties such as high mechanical properties, good thermal shock resistance and acceptable dielectric properties in the past decades [1,2]. In particular, silicon oxynitride ceramic with excellent oxidation resistance at severe conditions has gained much interest also [3]. Consequently, $\mathrm{Si}_{3} \mathrm{~N}_{4} / \mathrm{Si}_{2} \mathrm{~N}_{2} \mathrm{O}$ ceramics with a modified microstructure have been found to combine desirable properties such as the oxidation resistance of $\mathrm{Si}_{2} \mathrm{~N}_{2} \mathrm{O}$ and the strength of $\mathrm{Si}_{3} \mathrm{~N}_{4}$ [4].

Porous ceramics with a tailored microstructure are promising high-performance materials because of such unique properties as light weight, good strain tolerance, damage tolerance and thermal shock resistance $[5,6]$. In general, porous $\mathrm{Si}_{3} \mathrm{~N}_{4} / \mathrm{Si}_{2} \mathrm{~N}_{2} \mathrm{O}$ ceramics have been used as hot gas filters and catalyst supports [7]. Recently, porous $\mathrm{Si}_{3} \mathrm{~N}_{4} / \mathrm{Si}_{2} \mathrm{~N}_{2} \mathrm{O}$ ceramic is also attractive in electromagnetic wave penetrating materials, as a strategy to reduce dielectric constant [8].

Aqueous gelcasting allows obtaining complex-shaped parts with high density, low cost, machinable property and higher reliability of the formed green bodies [9-11]. Many studies have been done to promote the gelcasting process, however, it is still difficult to obtain concentrated $\mathrm{Si}_{3} \mathrm{~N}_{4}$ based suspensions with a solids loading above $50 \mathrm{vol} \%[10,11]$. So, the shrinkage of ceramic is a bit

\footnotetext{
* Corresponding author. Tel.: +86 451 86414291; fax: +86 45186414291 .

E-mail address: dcjia@hit.edu.cn (D. Jia).
}

large during sintering. Sol-gel infiltration has been widely used to increase the density, mechanical and thermal properties of various materials [12]. Nevertheless, it appears that there are few reports on fabricating of $\mathrm{Si}_{3} \mathrm{~N}_{4} / \mathrm{Si}_{2} \mathrm{~N}_{2} \mathrm{O}$ ceramics by silica sol infiltration method.

The aim of this work is to improve the colloidal forming process to manufacture low shrinkage porous $\mathrm{Si}_{3} \mathrm{~N}_{4} / \mathrm{Si}_{2} \mathrm{~N}_{2} \mathrm{O}$ ceramic parts. For this purpose, silica sol infiltration has been conducted on porous $\mathrm{Si}_{3} \mathrm{~N}_{4}$ ceramic prepared in aqueous gelcasting to get higher green density. So that suitable properties are achieved with lower shrinkage during sintering compared with aqueous gelcasting method. And we investigated the effect of infiltration cycles and sintering temperature on microstructures, mechanical and dielectric properties of the composite ceramics.

\section{Experimental procedure \\ 2.1. Materials processing}

Silicon nitride green bodies were obtained by aqueous gelcasting method using agarose solutions described elsewhere [13], and 6 wt.\% $\mathrm{Y}_{2} \mathrm{O}_{3}$ (99.9\%, Shanghai Yuelong Chemical Factory, Shanghai, China) +2 wt.\% $\mathrm{Al}_{2} \mathrm{O}_{3}$ (99.5\%, Beijing Chemical Factory, Beijing, China) were added as sintering aids. The compacts were first partially sintered to $46 \%$ of the theoretical density at $1350{ }^{\circ} \mathrm{C}$ for $0.5 \mathrm{~h}$ under a pressure of $0.1 \mathrm{MPa}$ in nitrogen. Then, the presintered porous $\mathrm{Si}_{3} \mathrm{~N}_{4}$ specimens $(55 \mathrm{~mm}$ in diameter and $6.5 \mathrm{~mm}$ in thickness) were infiltrated with silica sol solution in a vaccum atmosphere. Chemical compositions and properties of the silica sol (Huanqiu Chemical Factory, Jiangsu, China) are shown in Table 1. The specimens were placed in a vacuum chamber. After the chamber was evacuated, the silica sol was filled into the chamber and held for $2 \mathrm{~h}$. The silica sol contained compacts were gelled at $60{ }^{\circ} \mathrm{C}$ for $20 \mathrm{~h}$ and dried at $120^{\circ} \mathrm{C}$ for $4 \mathrm{~h}$ to remove the solvents. The treatment procedure of impregnation, gelling and drying, namely cycle of infiltration procedure, 
Table 1

Chemical compositions and properties of silica sol.

\begin{tabular}{lllll}
\hline $\mathrm{SiO}_{2}$ (wt.\%) & $\mathrm{Na}_{2} \mathrm{O}$ (wt.\%) & $\mathrm{pH}$ & Density $\left(\mathrm{g} \mathrm{cm}^{-3}\right)$ & Viscosity (mPa s) \\
\hline 45 & $<0.25$ & 9.33 & 1.30 & 12 \\
\hline
\end{tabular}

was repeated several times, to increase the silica content in the infiltrated samples. For comparison, one batch without silica sol infiltration was also prepared as a reference sample. Finally, the pellets were packed in a powder bed with a composition of $\mathrm{Si}_{3} \mathrm{~N}_{4}+50 \mathrm{vol} \% \mathrm{BN}$ in a graphite crucible and sintering was carried out in a gas pressure furnace at $1550^{\circ} \mathrm{C}, 1600^{\circ} \mathrm{C}$ and $1650^{\circ} \mathrm{C}$, respectively, for $1 \mathrm{~h}$ under a pressure of $0.1 \mathrm{MPa}$ in nitrogen. So, the specimens were designated as SN1550/0, SN1550/1, SN1550/2, SN1550/3, SN1600/2 and SN1650/2, respectively, for different sintering temperatures and infiltration cycles, which are shown in Table 2.

\subsection{Materials characterization}

Bulk density was calculated from measured dimension and weight. Due to neglectable volume shrinkage between reaction of $\mathrm{Si}_{3} \mathrm{~N}_{4}$ and $\mathrm{SiO}_{2}$ to form $\mathrm{Si}_{2} \mathrm{~N}_{2} \mathrm{O}$, the porosity was also calculated. Flexural strength was measured on a mechanical testing machine (Shimadzu, AG-Is50) using bar samples of $36 \mathrm{~mm} \times 4 \mathrm{~mm} \times 3 \mathrm{~mm}$ on a three-point bending fixture with a span length of $30 \mathrm{~mm}$ and a cross-head speed of $0.5 \mathrm{~mm} / \mathrm{min}$. Young's modulus was determined from the stress-strain curves obtained from load versus deflection plot. Each value was averaged of five measurements. Crystalline phases were identified by X-ray diffractometry (XRD, Rigaku, RINT-2000), using CuK $\alpha$ radiation at $40 \mathrm{kV}$ and $30 \mathrm{~mA}$. Microstructure was characterized by scanning electron microscopy (SEM, FEI, Quanta-200). Thermal expansion of the specimens was measured between $35^{\circ} \mathrm{C}$ and $800^{\circ} \mathrm{C}$ using thermal dilatometer (Netzsch, DIL-402C). Permittivity of the specimens with a size of $\Phi 18.0 \mathrm{~mm} \times 1.8 \mathrm{~mm}$ was measured in the frequency range of $21 \mathrm{GHz}$ to $38 \mathrm{GHz}$ at room temperature by RF impedance/material analyzer (Model 4291B, Agilent, USA).

\section{Results and discussion}

\subsection{Density}

Variations in the density of the infiltrated samples before and after sintering with the infiltration cycles are shown in Table 2. As expected, the density of green bodies increases with number of infiltration cycles and the density of all sintered samples ranges from $1.49 \mathrm{~g} \mathrm{~cm}^{-3}$ to $2.05 \mathrm{~g} \mathrm{~cm}^{-3}$. Clearly, density difference sharply increases after the first infiltration cycle, but is insensitive to further infiltrations after the second cycle. It can be considered that the pores of the composite have been blocked by the silica particles after the first two infiltrations and deposition, and the silica sol particle size is too large to infiltrate into the compact in the next cycles [7]. Furthermore, according to the weight increase after infiltrations for three times, the final mole ratio of $\mathrm{Si}_{3} \mathrm{~N}_{4}$ to $\mathrm{SiO}_{2}$ of the infiltrated sample is about 1:0.6. In addition, linear shrinkages are below $6 \%$ for all sintered samples because of partial sintering with low sintering temperature. These results mean better precision in the dimensional control that opens an opportunity to the industrial viability of aqueous gelcasting for manufacturing complex-shaped parts.

SEM fracture surface of green bodies with and without infiltration is shown in Fig. 1. After one infiltration cycle, $\mathrm{Si}_{3} \mathrm{~N}_{4}$ particles tend to be bonded by silica gel, exhibiting a more dense morphology as most small voids derived from the stack of $\mathrm{Si}_{3} \mathrm{~N}_{4}$ particles were filled with silica gel [14]. Furthermore, the fracture surface from
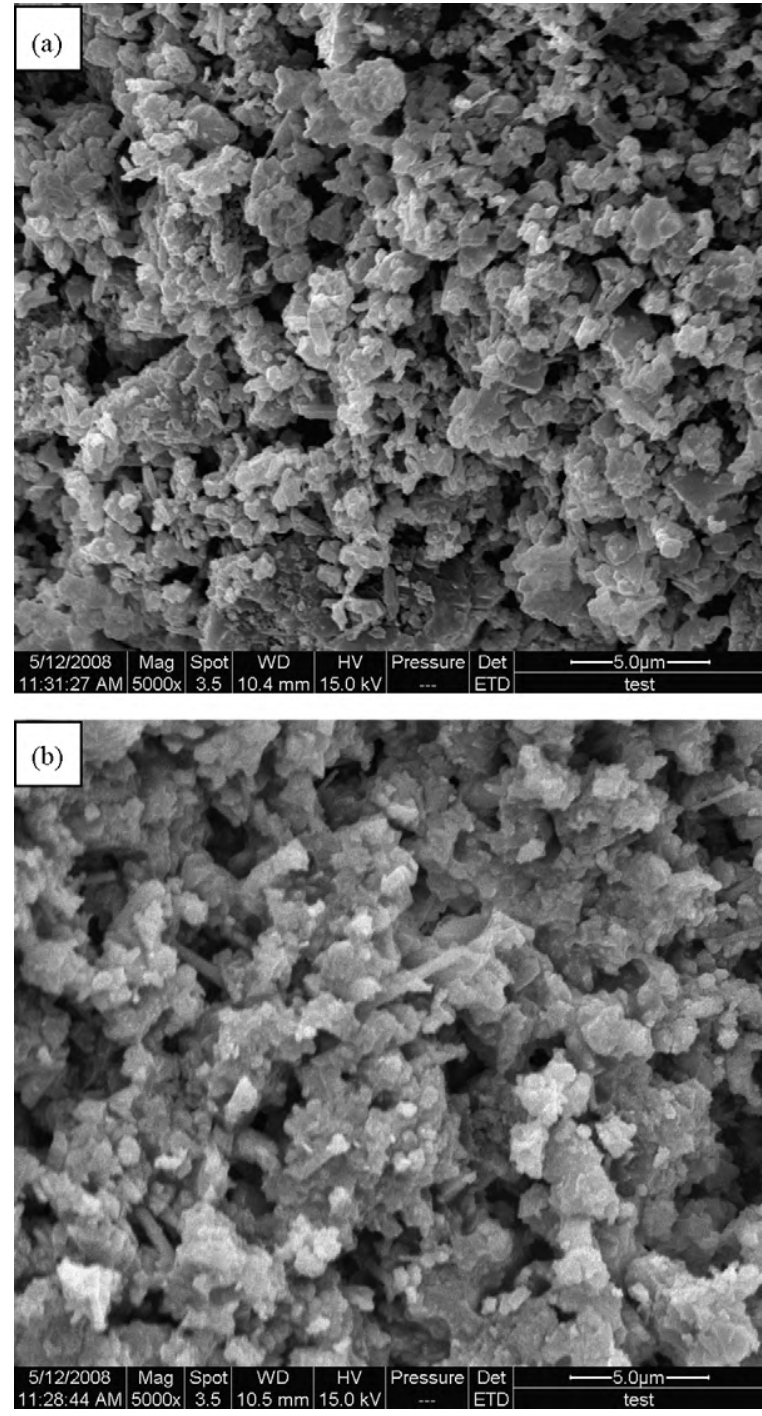

Fig. 1. SEM fracture surface of green bodies (a) prepared with partial sintering at $1350^{\circ} \mathrm{C}(\mathrm{b})$ after one infiltration cycle of $(\mathrm{a})$.

the interior to the exterior region of the compact after infiltration is the same, implying uniform microstructure.

\subsection{Phase composition and microstructure}

The XRD patterns of the composite ceramics with and without silica sol infiltration sintered at $1550^{\circ} \mathrm{C}$ are shown in Fig. 2 . It is revealed that $\alpha-\mathrm{Si}_{3} \mathrm{~N}_{4}$ is the main phase in all samples due to the low sintering temperature. Crystalline silica is not detected as $\mathrm{SiO}_{2}$ formed a liquid glass phase at $>1500{ }^{\circ} \mathrm{C}$ by reaction with $\mathrm{Al}_{2} \mathrm{O}_{3}$. It is similar with $\mathrm{SiO}_{2}$ particle doped $\mathrm{Si}_{3} \mathrm{~N}_{4}$ ceramics [15]. $\mathrm{Y}_{5} \mathrm{Si}_{3} \mathrm{O}_{12} \mathrm{~N}$ (JCPDS 48-1625) is found in sample without infiltration, but it van-

Table 2

Bulk density and linear shrinkage of the Si3N4/Si2N2O composite ceramics sintered at different temperatures and with different pre-infiltration cycles.

\begin{tabular}{|c|c|c|c|c|c|}
\hline \multirow[t]{2}{*}{ Specimens } & \multirow[t]{2}{*}{ Sintering temperature $\left({ }^{\circ} \mathrm{C}\right)$} & \multirow[t]{2}{*}{ Infiltration cycles } & \multicolumn{2}{|c|}{ Bulk density $\left(\mathrm{g} \mathrm{cm}^{-3}\right)$} & \multirow[t]{2}{*}{ Linear shrinkage (\%) } \\
\hline & & & Green & As-sintered & \\
\hline SN1550/0 & 1550 & 0 & 1.49 & 1.52 & 0.2 \\
\hline SN1550/1 & 1550 & 1 & 1.72 & 1.75 & 1.3 \\
\hline SN1550/2 & 1550 & 2 & 1.82 & 1.87 & 1.9 \\
\hline SN1550/3 & 1550 & 3 & 1.82 & 1.87 & 1.9 \\
\hline SN1600/2 & 1600 & 2 & 1.82 & 1.92 & 2.7 \\
\hline SN1650/2 & 1650 & 2 & 1.82 & 2.05 & 5.7 \\
\hline
\end{tabular}




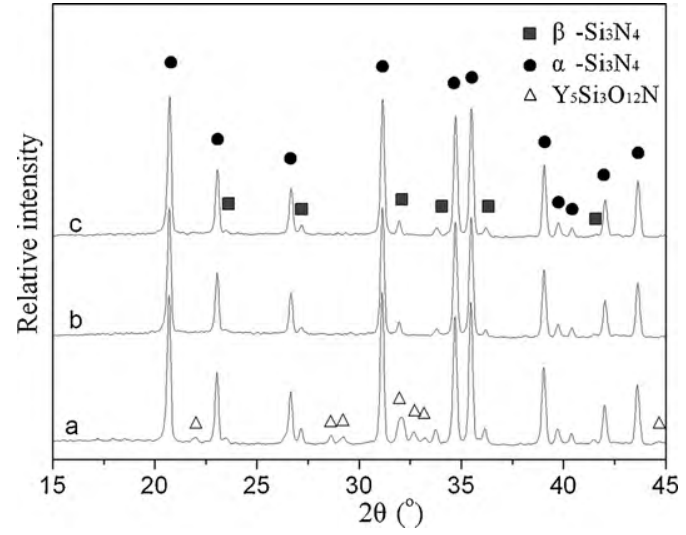

Fig. 2. XRD patterns of the porous $\mathrm{Si}_{3} \mathrm{~N}_{4}$ ceramics sintered at $1550{ }^{\circ} \mathrm{C}$ with different infiltration cycles: (a) none, (b) one, and (c) three.

ishes in the samples infiltrated with silica sol. It can be explained that $\mathrm{Y}_{5} \mathrm{Si}_{3} \mathrm{O}_{12} \mathrm{~N}$ is precipitated from the $\mathrm{Y}-\mathrm{Si}-\mathrm{Al}-\mathrm{O}-\mathrm{N}$ glass consisted of $\mathrm{Si}_{3} \mathrm{~N}_{4}, \mathrm{Y}_{2} \mathrm{O}_{3}$ and $\mathrm{Al}_{2} \mathrm{O}_{3}$. When silica is introduced, it greatly increases silicon and oxygen content in the liquid system. And this increase suppresses the precipitation of $\mathrm{Y}_{5} \mathrm{Si}_{3} \mathrm{O}_{12} \mathrm{~N}$. In other words, the sintering aids of $\mathrm{Y}_{2} \mathrm{O}_{3}$ and $\mathrm{Al}_{2} \mathrm{O}_{3}$ are dissolved into $\mathrm{SiO}_{2}$ at high temperature which presented as an amorphous phase finally [16].

The XRD patterns of the composite ceramics sintered at different temperatures are shown in Fig. 3. $\mathrm{Si}_{2} \mathrm{~N}_{2} \mathrm{O}$ (JCPDS 47-1627) formed through reaction between $\mathrm{Si}_{3} \mathrm{~N}_{4}$ and silica sol at a temperature above $1550{ }^{\circ} \mathrm{C}$. The content of $\mathrm{Si}_{2} \mathrm{~N}_{2} \mathrm{O}$ is increased with increasing sintering temperature because that more liquid phase can enhance the reaction to form $\mathrm{Si}_{2} \mathrm{~N}_{2} \mathrm{O}$. And the transformation of $\alpha-\mathrm{Si}_{3} \mathrm{~N}_{4}$ to $\beta-\mathrm{Si}_{3} \mathrm{~N}_{4}$ can also coincide with the formation of $\mathrm{Si}_{2} \mathrm{~N}_{2} \mathrm{O}$.

SEM fracture surfaces of $\mathrm{Si}_{3} \mathrm{~N}_{4} / \mathrm{Si}_{2} \mathrm{~N}_{2} \mathrm{O}$ composite ceramics sintered at different temperatures and with different pre-infiltration cycles are provided in Fig. 4. As it shown, the grains of uninfiltrated sample SN1550/0 are small and the particles contact each other loosely because nearly no further densification is achieved. Due to the weak bonding between grains, SN1550/0 is fractured inter-granularly. Infiltrated samples SN1550/2 seem to be denser, compared with the uninfiltrated one and this could be confirmed by density testing results. When the sintering temperature increases to above $1550^{\circ} \mathrm{C}$, the grains grow up and become coarsened. Ceramic particles are bonded by the thicker necks, possibly due to reaction between $\mathrm{Si}_{3} \mathrm{~N}_{4}$ and $\mathrm{SiO}_{2}$ to form $\mathrm{Si}_{2} \mathrm{~N}_{2} \mathrm{O}$, resulting in a strong network structure. The morphology of fracture surfaces of SN1600/2 and SN1650/2 are quite smooth suggesting a typical transgranular fracture mode.

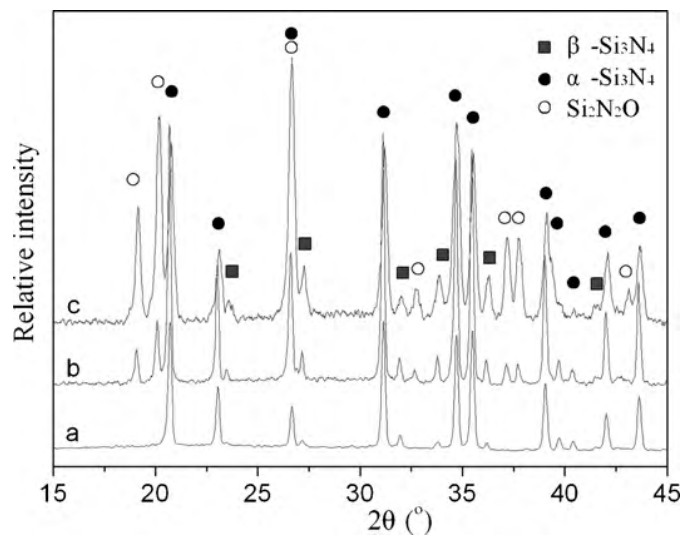

Fig. 3. XRD patterns of the $\mathrm{Si}_{3} \mathrm{~N}_{4} / \mathrm{Si}_{2} \mathrm{~N}_{2} \mathrm{O}$ composite ceramics sintered at different temperatures: (a) $1550^{\circ} \mathrm{C}$, (b) $1600^{\circ} \mathrm{C}$, and (c) $1650^{\circ} \mathrm{C}$.
Table 3

Variations in flexural strength and Young's modulus values versus with sintering temperature and silica sol infiltration cycles.

\begin{tabular}{lccl}
\hline Specimens & Young's modulus (GPa) & Flexural strength (MPa) & Porosity (\%) \\
\hline SN1550/0 & $26.4 \pm 0.7$ & $45.1 \pm 3.7$ & 53.1 \\
SN1550/1 & $48.0 \pm 1.2$ & $94.7 \pm 6.6$ & 46.0 \\
SN1550/2 & $58.4 \pm 2.0$ & $119.0 \pm 3.9$ & 42.3 \\
SN1600/2 & $81.0 \pm 1.2$ & $142.4 \pm 10.3$ & 40.7 \\
SN1650/2 & $106.3 \pm 5.5$ & $180.5 \pm 8.7$ & 36.7 \\
\hline
\end{tabular}

Table 4

Selected properties of $\mathrm{Si}_{2} \mathrm{~N}_{2} \mathrm{O}, \mathrm{Si}_{3} \mathrm{~N}_{4}$ and $\mathrm{SiO}_{2}$ ceramics.

\begin{tabular}{lccc}
\hline Properties & $\mathrm{Si}_{2} \mathrm{~N}_{2} \mathrm{O}$ & $\mathrm{Si}_{3} \mathrm{~N}_{4}$ & Fused $\mathrm{SiO}_{2}$ \\
\hline$\rho\left(\mathrm{g} \mathrm{cm}^{-3}\right)$ & 2.81 & 3.18 & 2.2 \\
$E(\mathrm{GPa})$ & 289 & 320 & 70 \\
$\sigma_{f}(\mathrm{MPa})$ & 513 & 700 & 50 \\
$\mathrm{CTE}\left(10^{-6}{ }^{\circ} \mathrm{C}^{-1}\right)$ & 3.3 & 3.2 & 0.55 \\
\hline
\end{tabular}

\subsection{Mechanical and thermal shock properties}

Variations in flexural strength and Young's modulus values versus sintering temperature and infiltration cycles are shown in Table 3. As indicated, the strength and Young's modulus increase with infiltration cycle as density of the sample is increased.

It is consistent with the empirical relation that flexural strength and Young's modulus increased with density [17]. This difference can also be explained when calculated flexural strength and Young's modulus values using mixed rule based on the property data of $\mathrm{Si}_{2} \mathrm{~N}_{2} \mathrm{O}, \mathrm{Si}_{3} \mathrm{~N}_{4}$ and $\mathrm{SiO}_{2}$ shown in Table 4. The values increased once the reaction between $\mathrm{Si}_{3} \mathrm{~N}_{4}$ and $\mathrm{SiO}_{2}$ take place to form $\mathrm{Si}_{2} \mathrm{~N}_{2} \mathrm{O}$. Furthermore, the standard deviation of the as-sintered sample is moderate suggesting a homogeneous microstructure of the composite ceramics.

Ceramics might be subjected to thermal shock in their applications. The critical temperature difference $\left(\Delta T_{C}\right)$ for crack initiation by thermal shock can be estimated from:

$\Delta T_{C}=\frac{\sigma_{f}(1-v)}{\alpha E}$

where $\sigma_{f}$ is the fracture strength, $v$ is the Poisson's ratio (suppose 0.26 for all the samples) [18], $E$ is the Young's modulus, $\alpha$ is the thermal expansion coefficient. According to Table 5, the calculated $\Delta T_{C}$ value decreases with increasing sintering temperature from $1550^{\circ} \mathrm{C}$ to $1650^{\circ} \mathrm{C}$ unexpectedly. And it is contrary to previously reported results that many type of ceramics with high-porosity would exhibit a low resistance to crack initiation when compared with the low-porosity ones [19]. This difference can be understood when calculated CTE, $E$ and $\sigma_{f}$ values using mixed rule basing on the properties of $\mathrm{Si}_{2} \mathrm{~N}_{2} \mathrm{O}, \mathrm{Si}_{3} \mathrm{~N}_{4}$ and $\mathrm{SiO}_{2}$ shown in Table 4 , as $\sigma_{f}$ is increased less sensitive to reaction compared with that of $E$ and CTE, so the $\Delta T_{C}$ value is decreased with the reaction between $\mathrm{Si}_{3} \mathrm{~N}_{4}$ and $\mathrm{SiO}_{2}$ to form $\mathrm{Si}_{2} \mathrm{~N}_{2} \mathrm{O}$.

\subsection{Dielectric properties}

Besides mechanical properties, dielectric constant is an important performance parameter for wave transparent applications. Fig. 5 shows the dielectric constant $\varepsilon$ of the as-prepared

Table 5

CTE and calculated critical temperature difference of porous $\mathrm{Si}_{3} \mathrm{~N}_{4} / \mathrm{Si}_{2} \mathrm{~N}_{2} \mathrm{O}$ composite ceramics.

\begin{tabular}{lccc}
\hline Specimens & SN1550/2 & SN1600/2 & SN1650/2 \\
\hline Critical temperature difference $\left({ }^{\circ} \mathrm{C}\right)$ & 486.4 & 380.4 & 364.2 \\
CTE $\left(10^{-6}{ }^{\circ} \mathrm{C}^{-1}\right)$ & 3.10 & 3.42 & 3.45 \\
\hline
\end{tabular}



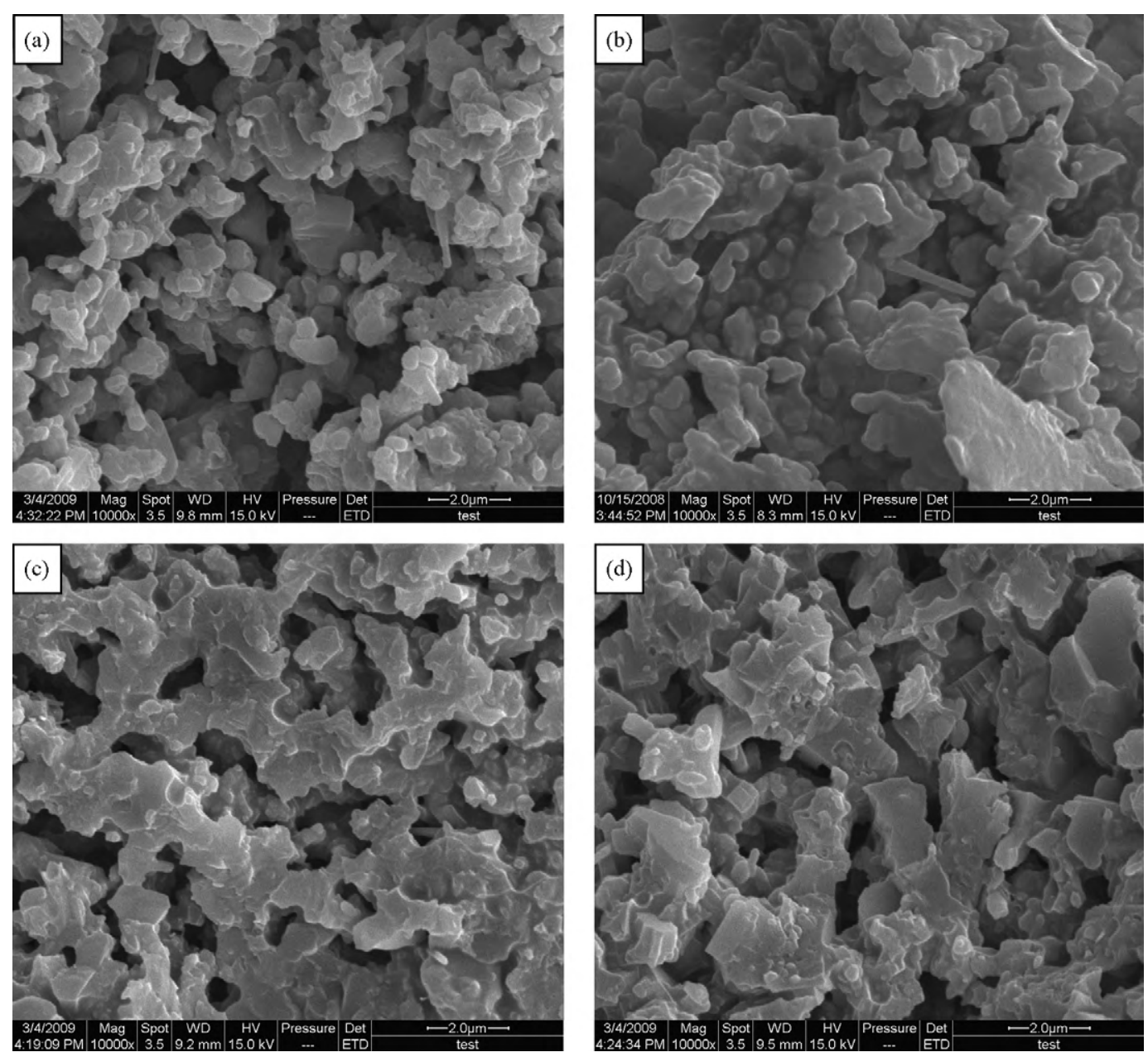

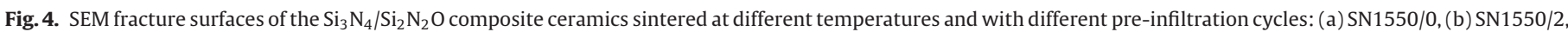
(c) SN1600/2, and (d) SN1650/2.

$\mathrm{Si}_{3} \mathrm{~N}_{4} / \mathrm{Si}_{2} \mathrm{~N}_{2} \mathrm{O}$ composite ceramics increase with sintering temperature and infiltration number. There are two reasons influencing the dielectric constant of the composite. One is the density, as the reaction between $\mathrm{Si}_{3} \mathrm{~N}_{4}$ and $\mathrm{SiO}_{2}$ to form $\mathrm{Si}_{2} \mathrm{~N}_{2} \mathrm{O}$ is almost no volume change (based on the property data of $\mathrm{Si}_{2} \mathrm{~N}_{2} \mathrm{O}, \mathrm{Si}_{3} \mathrm{~N}_{4}$ and $\mathrm{SiO}_{2}$ shown in Table 4), so, it is consistent with the empirical relation that dielectric constant increased with density according to Table 2 . The other is different relative content of $\alpha-\mathrm{Si}_{3} \mathrm{~N}_{4}, \beta-\mathrm{Si}_{3} \mathrm{~N}_{4}, \mathrm{Si}_{2} \mathrm{~N}_{2} \mathrm{O}$ and amorphous $\mathrm{SiO}_{2}$ phases among the composite ceramics [20], which is influenced by the reaction between $\mathrm{Si}_{3} \mathrm{~N}_{4}$ and $\mathrm{SiO}_{2}$.

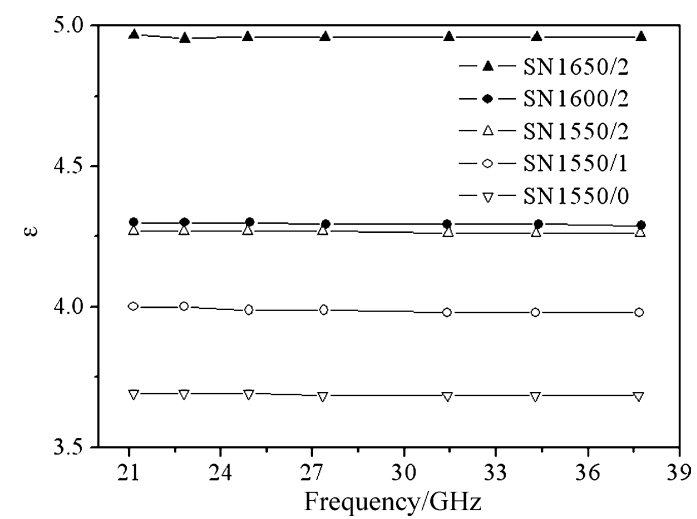

Fig. 5. Variations in dielectric constant values versus with sintering temperature and infiltration cycles.
Now, we calculated dielectric constant of an equimolar mixture of $\alpha-\mathrm{Si}_{3} \mathrm{~N}_{4}\left(\varepsilon_{\mathrm{SN}}=5.6\right)$ and $\mathrm{SiO}_{2}\left(\varepsilon_{\mathrm{SO}}=3.3\right)$ using Maxwell-Garnet rule (Eq. (2)), a typically host-inclusion model, to see how the dielectric constant changing with the reaction between $\mathrm{Si}_{3} \mathrm{~N}_{4}$ and $\mathrm{SiO}_{2}$ to form $\mathrm{Si}_{2} \mathrm{~N}_{2} \mathrm{O}$ :

$\varepsilon=\frac{v_{\mathrm{SN}} \varepsilon_{\mathrm{SN}}\left(\frac{2}{3}+\frac{\varepsilon_{\mathrm{SO}}}{3 \varepsilon_{\mathrm{SN}}}\right)+v_{\mathrm{SO}} \varepsilon_{\mathrm{SO}}}{v_{\mathrm{SN}}\left(\frac{2}{3}+\frac{\varepsilon_{\mathrm{SO}}}{3 \varepsilon_{\mathrm{SN}}}\right)+v_{\mathrm{SO}}}$

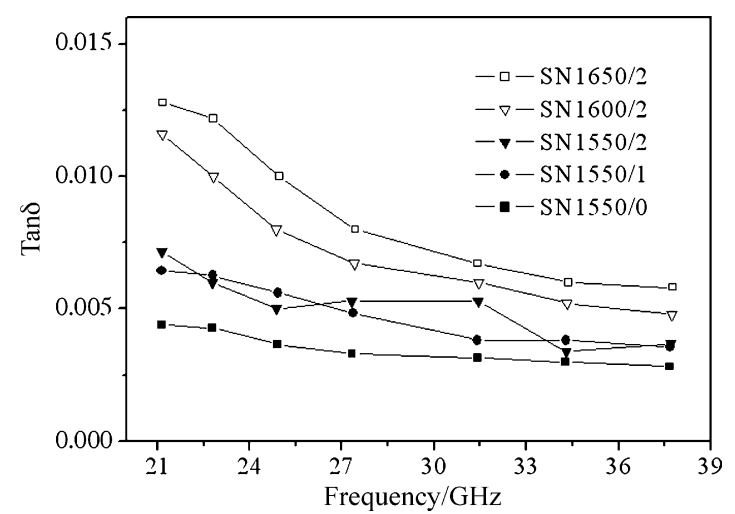

Fig. 6. Variations in dielectric loss tangent values versus with sintering temperature and infiltration cycles. 
Here, $\varepsilon$ denotes the relative permittivity of the mixture, and the volume fraction is represented as $v_{\mathrm{SN}}$ and $v_{\mathrm{SO}}$ for the $\mathrm{Si}_{3} \mathrm{~N}_{4}$ and $\mathrm{SiO}_{2}$, respectively. The result of $\varepsilon$ is 4.64 , comparing with the work of Tong et al. in $\mathrm{Li}_{2} \mathrm{O}$ doped $\mathrm{Si}_{2} \mathrm{~N}_{2} \mathrm{O}$ [21], the effect of the reaction between $\mathrm{Si}_{3} \mathrm{~N}_{4}$ and $\mathrm{SiO}_{2}$ on composite dielectric constant can be ignored, so, density increase is believed to be a major factor which influences the dielectric constant.

Generally, the dielectric loss tangent, $\tan \delta$, of the corresponding ceramics decreases continuously with increasing frequency as shown in Fig. 6. The value of loss tangent is below 0.013 which is suitable for its potential applications in the frequency range of 21-39 GHz. In addition, the dielectric loss increases with sintering temperature and infiltration number, which is consistent with the changes of the dielectric constant.

\section{Conclusions}

In this study, using gelcasting and silica sol infiltration method, we have fabricated porous silicon nitride/silicon oxynitride composite ceramics with low linear shrinkages, which ensuring better dimension controllability for manufacturing complexshaped parts. Suitable properties with low shrinkage of ceramics were obtained through increasing the green density of specimens. Mechanical properties of the ceramic are increased with infiltration cycles and sintering temperature as ceramic density is increased. The critical temperature difference and the dielectric properties can be tailored in a certain range by this method. So, we can get $\mathrm{Si}_{3} \mathrm{~N}_{4} / \mathrm{Si}_{2} \mathrm{~N}_{2} \mathrm{O}$ composite ceramic with excellent overall performance of strength, thermal shock resistance and dielectric properties.

\section{Acknowledgements}

This work was supported by the National Natural Science Foundation of China (NSFC, Grant No. 90505011), Program of Excellent Team in Harbin Institute of Technology and the Science Fund for Distinguished Young Scholars of Heilongjiang province.

\section{References}

[1] F.L. Riley, Silicon nitride and related materials, J. Am. Ceram. Soc. 83 (2000) 245-265.
[2] K.S. Mazdiyasni, R. Ruh, High-low modulus $\mathrm{Si}_{3} \mathrm{~N}_{4}-\mathrm{BN}$ composite for improved electrical and thermal-shock behavior, J. Am. Ceram. Soc. 64 (1981) 415419.

[3] M. Ohashi, S. Kanzaki, H. Tabata, Processing, mechanical properties, and oxidation behavior of silicon oxynitride ceramics, J. Am. Ceram. Soc. 74 (1991) 109-114.

[4] M. Radwan, T. Kashiwagi, Y. Miyamoto, New synthesis route for $\mathrm{Si}_{2} \mathrm{~N}_{2} \mathrm{O}$ ceramics based on desert sand, J. Eur. Ceram. Soc. 23 (2003) 2337-2341.

[5] Y. Inagaki, T. Ohji, S. Kanzaki, Y. Shigegaki, Fracture energy of an aligned porous silicon nitride, J. Am. Ceram. Soc. 83 (2000) 1807-1809.

[6] C. Kawai, A. Yamakawa, Effect of porosity and microstructure on the strength of $\mathrm{Si}_{3} \mathrm{~N}_{4}$ : designed microstructure for high strength, high thermal shock resistance, and facile machining, J. Am. Ceram. Soc. 80 (1997) 27052708.

[7] R.K. Paul, C.W. Lee, H.D. Kim, B.T. Lee, Microstructure characterization of in situ synthesized porous $\mathrm{Si}_{3} \mathrm{~N}_{4}-\mathrm{Si}_{2} \mathrm{~N}_{2} \mathrm{O}$ composites using feldspar additive, J. Mater. Sci. 42 (2007) 4701-4706.

[8] S.Q. Li, Y.C. Pei, C.Q. Yu, J.L. Li, Mechanical and dielectric properties of porous $\mathrm{Si}_{2} \mathrm{~N}_{2} \mathrm{O}-\mathrm{Si}_{3} \mathrm{~N}_{4}$ in situ composites, Ceram. Int. 35 (2009) 18511854.

[9] I. Santacruz, M.I. Nieto, R. Moreno, Alumina bodies with near-to-theoretical density by aqueous gelcasting using concentrated agarose solutions, Ceram. Int. 31 (2005) 439-445.

[10] J.Q. Dai, Y. Huang, Z.P. Xie, X.L. Xu, J.L. Yang, Effect of acid cleaning and calcination on rheological properties of concentrated aqueous suspensions of silicon nitride powder, J. Am. Ceram. Soc. 85 (2002) 293-298.

[11] Y. Huang, L.J. Zhou, Q. Tang, Z.P. Xie, J.L. Yang, Water-based gelcasting of surface-coated silicon nitride powder, J. Am. Ceram. Soc. 84 (2001) 701707.

[12] S. Taktak, M.S. Baspinar, Wear and friction behaviour of alumina/mullite composite by sol-gel infiltration technique, Mater. Design 26 (2005) 459464.

[13] Y.F. Shao, D.C. Jia, Y. Zhou, B.Y. Liu, Novel method for fabrication of silicon nitride/silicon oxynitride composite ceramic foams using fly ash cenosphere as a pore-forming agent, J. Am. Ceram. Soc. 91 (2008) 3781-3785.

[14] M. Luo, J.Q. Gao, J.F. Yang, Biomorphic silicon nitride ceramics with fibrous morphology prepared by sol infiltration and reduction-nitridation, J. Am. Ceram. Soc. 90 (2007) 4036-4039.

[15] M. Mitomo, S. Ono, T. Asami, S.J.L. Kang, Effect of atmosphere on the reaction sintering of $\mathrm{Si}_{2} \mathrm{~N}_{2} \mathrm{O}$, Ceram. Int. 15 (1989) 345-350.

[16] C. O'Meara, G.L. Dunlop, R. Pompe, Formation, crystallisation and oxidation of selected glasses in the Y-Si-Al-O-N, J. Eur. Ceram. Soc. 8 (1991) 161170.

[17] A. Diaz, S. Hampshire, Characterisation of porous silicon nitride materials produced with starch, J. Eur. Ceram. Soc. 24 (2004) 413-419.

[18] J.H. She, J.F. Yang, D.D. Jayaseelan, N. Kondo, T. Ohji, S. Kanzaki, Thermal shock behavior of isotropic and anisotropic porous silicon nitride, J. Am. Ceram. Soc. 86 (2003) 738-740.

[19] J.H. She, J.F. Yang, T. Ohji, Thermal shock resistance of porous silicon nitride ceramics, J. Mater. Sci. Lett. 22 (2003) 331-333.

[20] J.Q. Li, F. Luo, M.D. Zhu, W.C. Zhou, Influence of phase formation on dielectric properties of $\mathrm{Si}_{3} \mathrm{~N}_{4}$ ceramics, J. Am. Ceram. Soc. 90 (2007) 1950-1952.

[21] Q.F. Tong, J.Y. Wang, Z.P. Li, Y.C. Zhou, Low-temperature synthesis/densification and properties of $\mathrm{Si}_{2} \mathrm{~N}_{2} \mathrm{O}$ prepared with $\mathrm{Li}_{2} \mathrm{O}$ additive, J. Eur. Ceram. Soc. 27 (2007) 4767-4772. 